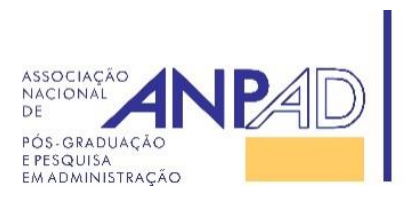
Disponível em
http://www.anpad.org.br/rac
RAC, Rio de Janeiro, v. 21, n. 4, art. 2,
pp. 458-480, Julho/Agosto, 2017

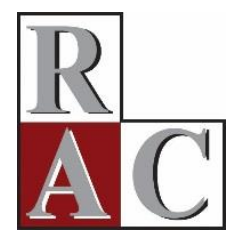

\title{
O Efeito da Publicação Científica do Orientador na Publicação dos Seus Orientados
}

The Effect of the Advisors' Competence in Scientific Publications Their Advisees'

Publication

\author{
Christian Falaster ${ }^{1}$ \\ Manuel Portugal Ferreira ${ }^{1,2}$ \\ Daniela Modolo Ribeiro de Gouvea ${ }^{1}$ \\ Universidade Nove de Julho ${ }^{1}$ \\ Instituto Politécnico de Leiria ${ }^{2}$
}

Artigo recebido em 13.05.2016. Última versão recebida em 30.10.2016. Aprovado em 15.11.2016. Publicado online em 20.03.2017. 


\title{
Resumo
}

Neste artigo analisamos o efeito da orientação na produção científica dos alunos de doutorado em Administração. A questão essencial de pesquisa é como a competência em produção científica (publicação de artigos) do professor orientador pode influenciar a produção dos orientados doutorados. Por meio de um estudo empírico quantitativo realizado com dados secundários numa base de 313 orientados e 127 professores orientadores de quatro universidades brasileiras, analisamos a relação entre o volume e qualidade das publicações do professor orientador com o volume e qualidade das publicações do orientado, utilizando regressões lineares múltiplas. Analisamos, assim, o impacto da orientação como preditor da competência de publicação futura dos doutores. Encontramos evidência de que há uma relação significativa entre a qualidade das publicações do orientador e a qualidade das publicações do orientado, mas não houve evidência de que exista uma influência sobre a quantidade de publicações do orientado doutorado. Este estudo contribui ao demonstrar que a produção científica do orientador - em termos de qualidade e quantidade - está diretamente ligada à do estudante, com implicações para os programas doutorais e para os estudos sobre a produção científica.

Palavras-chave: publicação científica; relação orientador-orientado; qualidade da publicação, programas doutorais.

\begin{abstract}
This article analyzes the effect advising has on Management Ph.D student scientific publication. The research question is how an adviser's competence in scientific production (publication of articles) may influence their advisee's production. In an empirical study using secondary data of a sample of 313 new-PhDs and 127 professors from four Brazilian universities, we analyzed the relationship between the number and quality of adviser publications with the number and quality of advisee publications, using multiple linear regressions. We thus analyzed the impact adviser production has as a predictor of new-Ph.D.'s future publication competence. We found evidence for a significant relationship between quality of adviser publications and the quality of advisee publications, but not the quantity. This study contributes to demonstrate that the scientific production of advisers - in quality and quantity - is directly related to their students' future production, with implications for doctoral programs and for research on scientific production.
\end{abstract}

Key words: scientific publishing; adviser-student relations; publication quality; doctoral programs. 


\section{Introdução}

Publicar, além de uma função primordial, ou requisito, em muitos casos, da profissão de professor universitário, é também um desafio que os pesquisadores precisam vencer para sua empregabilidade em programas de pós-graduação stricto sensu (Galbraith, Smart, Smith, \& Reed, 2014) e para se desenvolver na carreira (Stephan, 1996). A capacidade ou competência de publicar é, assim, um dos focos de formação dos programas doutorais (Falaster, Ferreira, \& Serra, 2016), pois a qualidade da formação pode indiciar o futuro desempenho de publicação dos pesquisadores (Conley \& Önder, 2014). Dessa forma, observar a relação entre a produção científica (publicações de artigos) dos professores orientadores e a produção científica futura dos seus estudantes de doutorado parece relevante. Ou seja, neste estudo sugerimos que a competência do professor orientador terá um impacto positivo na formação do estudante (Punyanunt-Carter \& Wrench, 2008), refletindo-se em sua produção científica. No presente artigo examinamos quais os efeitos da orientação na produtividade dos alunos de programas de doutorado em Administração no Brasil. Especificamente, investigamos se orientadores com maior quantidade e qualidade de publicações influenciam seus orientados a terem também maior qualidade e quantidade de publicações.

A relação entre professores orientadores e seus orientados já foi alvo de pesquisa. Por exemplo, Sheldon, Garton, Orr e Smith (2015) analisaram as qualidades do bom orientador; Punyanunt-Carter e Wrench (2008) investigaram os estilos de orientação focando a agressividade, credibilidade e conflito; e Brockman, Nunez e Basu (2010) exploraram a relação e especificamente o conflito entre orientadores e orientados. Tenenbaum, Crosby e Gliner (2001), Noy e Ray (2012), Paglis, Green e Bauer (2006) e Hilmer e Hilmer (2009) investigaram os efeitos da orientação na produtividade, eficiência e comprometimento pela carreira de pesquisa. Porém, há poucos estudos na literatura sobre a relação entre a produção científica do orientador e do orientando. Há uma exceção em Williamson e Cable (2003), que investigaram esta relação, entre várias outras, mas sem distinção de quantidade e qualidade de artigos do orientador e do orientando. No nosso conhecimento, esta pesquisa não foi realizada no Brasil.

O contexto Brasileiro da pós-graduação stricto sensu evidencia um grande aumento na formação de novos doutores e no volume de produção científica de artigos na última década. Por exemplo, em 2005, formaram-se, no Brasil, 117 doutores em Administração nos diversos programas doutorais, mas em 2015 se formaram 307 doutores em Administração (Plataforma Lattes, 2016). Também o volume da produção científica brasileira aumentou acompanhando a tendência de graduação e, em 2015, o Brasil foi classificado como o $15^{\circ}$ país com maior número de artigos científicos publicados (Scimago Journal \& Country Rank, 2007- 2016). Para esta evolução são relevantes as mudanças nos critérios de avaliação introduzidas pela Coordenação de Aperfeiçoamento de Pessoal de Nível Superior (CAPES), que vieram a, gradualmente, impor maiores exigências, incluindo de produção científica (Maccari, Rodrigues, Alessio, \& Quoniam, 2011). A maior ênfase na produção científica nas avaliações institucionais da CAPES tornou a pesquisa uma atividade central na carreira do professor de stricto sensu (Maccari et al., 2011; Nascimento, 2010). Os professores precisam atingir metas - qualitativas e quantitativas - de publicação para permanecerem nos programas (Trein \& Rodriguez, 2011).

Dadas as pressões organizacionais e institucionais para publicar nos programas stricto sensu, é relevante entender se e como a formação dos pesquisadores, em especial a sua formação durante os programas doutorais, influencia a capacidade futura de produzir trabalhos científicos em volume e nos padrões de qualidade exigidos pelos periódicos (Conley \& Önder, 2014; Falaster, Ferreira, \& Serra, 2016; Serra, Fiates, \& Ferreira, 2008). Neste contexto, sugerimos que a orientação terá um papel fundamental na formação do doutorando como futuro pesquisador (Hilmer \& Hilmer, 2009; Noy \& Ray, 2012), na medida em que o acadêmico adquirirá do seu orientador a habilidade de produzir artigos científicos (Punyanunt-Carter \& Wrench, 2008; Williamson \& Cable, 2003). Especificamente, neste estudo, investigamos se há, e como, uma relação entre a produção científica dos professores orientadores, distinguindo níveis de qualidade e de volume, e a produção científica futura dos seus estudantes de doutorado. Ou seja, o objetivo deste artigo é analisar o impacto da orientação como preditor da competência de publicação futura dos doutores em Administração. 
Este artigo contribui para a academia brasileira por oferecer evidências empíricas dos efeitos da orientação sobre o doutorando em formação, o que é particularmente aferido pela produção científica de artigos acadêmicos do pesquisador recém-doutorado. $\mathrm{O}$ estudo distingue produção científica em volume e qualidade, no que concerne à influência da orientação. Este artigo expande, assim, a discussão sobre a importância da orientação no curso de doutorado, no contexto da necessidade de publicação científica pelos novos doutores em Administração. Há, assim, uma contribuição não apenas para os professores pesquisadores e os estudantes de doutorado, mas também para os diretores de programas doutorais que necessitam atender às metas definidas pela CAPES e que poderão usar os resultados deste estudo para conceber ações concretas para a melhoria da produção científica nos programas que coordenam.

\section{Revisão de Literatura e Hipóteses}

Há décadas, a pesquisa se destaca como uma das principais atividades dos professores universitários, ainda que talvez mais notoriamente em países como os Estados Unidos e a Grã-Bretanha (Stahl, Leap, \& Wei, 1988). No Brasil, a necessidade de publicar artigos em periódicos avaliados por pares é mais recente, porém já é institucionalmente fundamental à profissão de professor, pelo menos para os professores de programas stricto sensu. A publicação científica dos docentes e discentes (estudantes) é um dos critérios em relação aos quais os programas são avaliados pelas agências reguladoras (Maccari et al., 2011). Assim, o pesquisador sente a necessidade de publicar para permanecer no sistema (Trein \& Rodriguez, 2011).

\section{Quadro institucional}

As pressões institucionais são um dos influenciadores do desempenho científico dos pesquisadores. No quadro institucional vigente, um dos critérios para avaliar o desempenho de programas e das universidades advém do desempenho dos professores em publicações (Witte \& Rogge, 2010). Assim, a universidade que tiver um corpo docente engajado em produzir um número considerável de artigos científicos e publicar em periódicos com revisão pelos pares de alto estatuto conseguirá se manter nos padrões de qualidade exigidos pelos órgãos reguladores (Maccari et al., 2011), atrair professores e recursos das agências de fomento.

No Brasil, a instituição responsável pela avaliação dos cursos de pós-graduação é a Capes. A Coordenação de Aperfeiçoamento de Pessoal de Nível Superior (Capes) é uma instituição governamental do Ministério da Educação (MEC) existente desde 1951. Nos últimos tempos, de acordo com Nascimento (2010), a Capes incrementou importantes mudanças em seu sistema de avaliação e, entre elas, há uma maior ênfase dada à produção científica, mais precisamente à publicação de artigos científicos. Por essa razão, professores pesquisadores têm optado por aumentar sua produção na elaboração de artigos científicos se compararmos com a participação em eventos científicos, uma vez que essa modalidade já não é mais tão valorizada. A Capes compreende um sistema de avaliação moderno e eficiente (Maccari et al., 2011) com referências e padrões advindos do modelo norteamericano.

Apesar de bastante avançado, o sistema de avaliação da CAPES não é isento de críticas (Nascimento, 2010), pois seus critérios de avaliação são baseados em métricas quantitativas que aumentam a pressão para publicação e geram críticas sobre ser um sistema que favorece o produtivismo. O produtivismo acadêmico (ver, por exemplo, Alcadipani, 2011) é aqui caracterizado como a geração de maior volume de artigos publicados, mas de qualidade inferior, sem contribuição teórica ou prática, apenas para o pesquisador vencer as exigências mínimas que lhe são impostas (Patrus, Dantas, \& Shigaki, 2015), seguindo a lógica do publicar ou perecer (publish or perish) (ver, a respeito, Harzing, 2010). Uma dinâmica produtivista pode ser prejudicial ao pleno desenvolvimento da ciência (Patrus et al., 2015) e evidencia ajustes necessários no sistema institucional brasileiro (Nascimento, 2010). 


\section{Os periódicos e sua classificação}

De forma geral, os pesquisadores buscam publicar as suas pesquisas (ou seja, os artigos) em periódicos que valorizem suas carreiras. Quanto maior for a classificação (ou estrato) do periódico em que publica, maior será o prestígio trazido para o pesquisador (Stephan, 1996). Dessa forma, publicar em periódicos de estratos altos pode melhorar a carreira e o reconhecimento dos pesquisadores brasileiros que atingem este feito (Ferreira, 2015). Porém, para publicar em estratos mais altos, é necessário lidar com níveis de exigência maiores, que incidem em um rigor teórico e metodológico apurado (Ferreira \& Falaster, 2016).

Internacionalmente, há diferentes práticas e diferentes classificações dos periódicos. Por exemplo, nos EUA é comum as universidades definirem colegialmente os rankings (Hotard, Tanner, \& Manakyan, 1996; Shugan, 2003), o que necessariamente conduzirá a diferenças assinaláveis na forma como é valorizada a publicação nos periódicos. Nos países europeus as práticas variam muito ente país e entre instituição. Algumas universidades não usam qualquer classificação, outras constroem classificações internas (ver a Journal quality list de Ann-Will Harzing), e ainda outras baseiam as avaliações nos fatores de impacto JCR dos periódicos. A indexação em bases de dados como a ISI ou a Scopus são critérios também usados para diferenciar qualidade. O sistema talvez mais usado é o do fator de impacto (impact factor) dos periódicos - que foi, também, introduzido na última revisão do Qualis.

Os periódicos brasileiros também têm se desenvolvido em torno de uma política institucional de classificação. No Brasil, o sistema adotado é o Qualis, que inclui periódicos nacionais e estrangeiros e é revisto periodicamente. O sistema Qualis da Capes, recentemente incorporado pelo sistema Sucupira, classifica os periódicos em oito estratos diferentes: A1, A2, B1, B2, B3, B4, B5 e C. Esta classificação dos periódicos leva em consideração uma série de indicadores, que partem de uma organização editorial e conceitos básicos de condução do periódico para os estratos mais baixos, até a necessidade de citações de acordo com o JCR e índice $\mathrm{H}$ para os periódicos de nível mais alto (para análise mais detalhada ver Ferreira, 2015). Uma gestão adequada do periódico pode, com algum esforço da instituição de ensino e da equipe editorial, garantir até mesmo um estrato consideravelmente alto (B2), mesmo sem que o periódico seja substancialmente citado (Ferreira, Canela, \& Pinto, 2014), ou seja, sem realmente se avaliar o impacto dos artigos que nele foram publicados. O impacto, entenda-se, é mensurado com base no número de citações que um dado artigo recebe e, no caso dos periódicos, nas citações aos artigos que publicou. Com base nessas condições, os periódicos brasileiros têm adotado políticas para melhorar sua qualidade e o estrato onde estão classificados (Ferreira, 2015).

\section{O papel do orientador na formação dos seus orientados}

A qualidade da formação recebida pelos alunos de pós-graduação em programas de doutorado pode ser relacionada ao seu sucesso futuro como pesquisadores (Conley \& Önder, 2014). Sendo o sucesso profissional cada vez mais aferido pelas publicações de artigos (embora existam outras vertentes igualmente importantes nas atividades dos professores pesquisadores), então, o desenvolvimento das competências necessárias para publicação (ver Serra et al., 2008) pode ser feito durante a formação de doutorado. Ou seja, as competências e habilidades necessárias para o pesquisador conseguir publicar na quantidade e qualidade necessária serão desenvolvidas, pelos menos em parte, durante a sua formação.

Certamente há múltiplos determinantes do desempenho em publicação de um estudante de pósgraduação depois de receber seu título de doutor. Alguns prendem-se com percursos profissionais porque nem todos os doutores prosseguem carreiras acadêmicas, não se interessando pela publicação científica nem por lecionar em programas de mestrado e doutorado. Mas há, também, os sistemas de incentivos das organizações que não promovem a pesquisa e publicação. Por exemplo, nos Estados Unidos é bem vincada a distinção entre as teaching e as research universities. Por esses fatores, importa aprofundar as gêneses das grandes disparidades entre os desempenhos de publicação dos doutores graduados (Hilmer \& Hilmer, 2009). Um aspecto que pode ser crucial é a orientação ou, especificamente, o impacto que o professor orientador tem sobre o desempenho dos seus orientados. 
O professor orientador desempenha um papel importante na formação do pesquisador (Punyanunt-Carter \& Wrench, 2008), ou seja, a relação entre professor orientador e orientado e a forma como trabalham podem melhorar as habilidades e a futura carreira do pesquisador (Sheldon, Garton, Orr, \& Smith, 2015). O nome alemão para o orientador de doutorado é Doktorvater, em outras palavras, pai doutor, sendo, assim, uma figura paternalista que guia o estudante de stricto sensu (Brockman, Nunez, \& Basu, 2010). A orientação, talvez mais especialmente em programas doutorais, é um processo de construção de conhecimento realizado pela interação entre o orientador e o estudante orientado. Nesse processo, o orientador é visto como o personagem que mantém uma relação complexa, intersubjetiva e rica em detalhes com os orientados (Paglis, Green, \& Bauer, 2006; Punyanunt-Carter \& Wrench, 2008; Tenenbaum, Crosby, \& Gliner, 2001). Dessa vivência resultam teses e dissertações que contribuem para o desenvolvimento e consolidação do conhecimento científico da área estudada (Leite \& Martins, 2006) e, previsivelmente, para o nível de competência do aprendiz. Assim, os programas doutorais confiam ao seu quadro de professores a missão de proporcionar uma boa orientação aos seus alunos; uma vez que um bom orientador pode ser um fator crucial para determinar o futuro sucesso dos alunos (Hilmer \& Hilmer, 2009; Punyanunt-Carter \& Wrench, 2008).

A pesquisa tem sido abundante sobre o papel dos orientadores. Por exemplo, os orientadores precisam ser mentores (Punyanunt-Carter \& Wrench, 2008), assegurar a formação geral dos alunos e ajudá-los a desenvolver uma rede de contatos e coautorias, a publicar e a obter financiamento em projetos (Noy \& Ray, 2012). Os orientadores que se fazem disponíveis e são experientes na pesquisa são capazes de ter melhores resultados com seus estudantes e tornar-se um recurso valioso para as suas universidades (Sheldon et al., 2015). Adicionalmente, os orientadores que trabalham com a ajuda na formação de redes de contatos e coautorias impactam positivamente na produtividade dos seus orientandos (Tenenbaum et al., 2001). Em outras palavras, os orientadores podem ser responsáveis pelo progresso do orientando, sua aprendizagem em pesquisa e seu sucesso no futuro (Punyanunt-Carter \& Wrench, 2008). Em suma, os estudos têm demonstrado que os orientadores e as experiências e o aprendizado durante a orientação têm um impacto positivo sobre muitos aspectos da vida acadêmica do orientado.

A pesquisa sobre o impacto da orientação na produção futura dos doutorados é muito limitada e não é conclusiva. Williamson e Cable (2003), por exemplo, investigaram a relação entre a produção do orientador e a produção futura do orientado, chegando à conclusão de que orientadores com alta produção levam seus estudantes a publicarem durante o doutorado, o que, por sua vez, também aumenta a sua publicação futura. Paglis et al. (2006) encontraram evidência de que os pesquisadores que tiveram melhor orientação durante o seu programa de doutorado tiveram melhores publicações em um prazo de cinco anos. Goldstein (1979) evidenciou que estudantes que têm orientadores do mesmo gênero tendem a publicar mais do que estudantes com orientadores de outro gênero. Hilmer e Hilmer (2009), por outro lado, demonstraram que estudantes medianos com orientadores de alto nível tendem a tornar-se bastante produtivos no futuro. No entanto, também identificaram que os melhores estudantes com orientadores medianos também tendem a tornar-se muito produtivos.

Sugerimos que é razoável esperar que haja um impacto positivo (negativo) do orientador na maior (menor) produção científica dos seus orientados de programas doutorais. Ou seja, que haja uma relação entre a qualidade da orientação - e mais especificamente do orientador - com a qualidade da formação dos estudantes. Dessa forma, esperamos que o nível das produções do recém-doutorado seja função da habilidade do professor orientador em desenvolver e publicar seus artigos. Em essência, partimos do pressuposto que o orientador efetivamente buscará orientar, ajudando os seus orientandos, e que a experiência em publicar do professor orientador determinará os conhecimentos que este pode ensinar ao aluno para a publicação de artigos. Assim, podemos postular que quanto maior o número de artigos publicados do orientador, maior sua experiência em publicação, incluindo todo o processo editorial (ver a respeito em Ferreira, 2013). Então, orientando os estudantes nos seus trabalhos de pesquisa, este orientador produtivo entenderá melhor o processo e as dificuldades e conseguirá utilizar a sua experiência e conhecimento para uma orientação mais eficaz. Ou seja, a experiência do orientador em publicação irá ajudar o orientado a escrever artigos de forma mais eficaz e melhor, influenciando a 
publicação do estudante de duas maneiras: melhorando a quantidade e a qualidade de seus artigos publicados.

Face ao exposto, formulamos três hipóteses que, no conjunto, preveem que o desempenho de publicação científica - em quantidade (i.e., número de artigos publicados) e qualidade (aferida pela classificação Qualis dos periódicos) dos artigos - dos estudantes orientados está positivamente relacionado com a competência de publicação científica do professor orientador. Deste modo, orientadores com maiores (volume) e melhores (qualidade) históricos de publicação graduarão novos doutores que serão, também eles, mais produtivos.

Hipótese 1. O número de publicações dos recém-doutorados orientados está positivamente relacionado com o volume e a qualidade das publicações do professor orientador.

De modo similar, parece razoável sugerir que haverá uma relação entre a qualidade dos artigos publicados pelo orientador e a produção do estudante. Sugerimos que professores orientadores que tendem a publicar em periódicos de níveis mais altos podem ter mais habilidade em conduzir pesquisas de alto nível e mais motivação para levar seus orientados a também publicar em periódicos de alto nível. É razoável também prever que orientadores que produzem pesquisas de nível, em média, maior, também terão mais expertise na publicação, compreendendo as novas tendências de publicação e os cuidados a ter para evitar a rejeição (Falaster, Ferreira, \& Canela, 2016). Em suma, sugerimos que a competência do orientador em escrever e publicar artigos em periódicos de estratos mais altos se refletirá de modo que os orientandos se foquem também neste nível de periódicos. Na forma de hipótese, poderíamos avançar que quanto maior for a qualidade média das publicações do orientador, maior será quer a qualidade média dos artigos do orientando, quer mesmo a quantidade de artigos publicados.

Avaliar a qualidade das publicações é uma tarefa sujeita a críticas (Selgen, 1997), mas é talvez menos sensível se tomarmos como referência as classificações existentes e os fatores de impacto. Estas classificações e fatores de impacto dos periódicos são comumente usados para aferir a qualidade dos artigos (Ferreira, 2015), apesar de todas as críticas (Nascimento, 2010; Rond \& Muller, 2005; Shugan, 2003).

Conforme Ferreira e Falaster (2016), a dificuldade de publicação aumenta para periódicos nos estratos mais altos, pelo menos em parte pela valorização relativa que é dada a diferentes componentes da pesquisa, como seja a sua contribuição teórica efetiva. Assim, publicar nos maiores estratos é uma tarefa difícil até mesmo para pesquisadores bastante experientes, e trabalhar nas fronteiras do conhecimento requer competências, ou habilidades, menos usuais (Serra et al., 2008). Desta forma, é possível postular que professores orientadores que têm as habilidades para produzir artigos em periódicos de topo - ou periódicos nos estratos mais altos e com maior impacto - podem transmitir essa competência aos seus orientados. Assim, podemos esperar que quanto maior a competência do orientador - aferida, por exemplo, pelo maior número de artigos publicados em estratos de topo do ranking (A1 e A2 no sistema Qualis, por exemplo), maior será também a qualidade dos artigos publicados pelos seus orientados. Avançamos, assim, com duas hipóteses.

Hipótese 2. A qualidade das publicações dos recém-doutorados orientados está positivamente relacionada com o volume e qualidade das publicações do professor orientador.

Hipótese 3. A qualidade das publicações dos recém-doutorados orientados está positivamente relacionada com o número de artigos de mais alta qualidade (publicados em periódicos do topo do ranking) pelo professor orientador.

\section{Método}

Metodologicamente, este artigo assenta num estudo empírico usando um banco de dados construído especificamente com elementos coletados dos currículos Lattes e do caderno de indicadores 
da Capes. A amostra inclui 127 professores orientadores e 313 doutores graduados entre 2009 e 2012, de quatro programas de doutorado em Administração (FGV/SP, FGV/RJ, UFMG e USP). Esta base de dados compreende especialmente métricas da produção científica - publicações de artigos em periódicos com revisão pelos pares - dos professores orientadores e dos seus orientados de doutorado.

\section{Procedimento de coleta de dados}

A coleta de dados envolveu quatro etapas. Primeiro, selecionamos quatro programas de doutorado de quatro universidades brasileiras classificados com conceitos 6 e 7 pela Capes: Universidade Federal de Minas Gerais (UFMG), Fundação Getúlio Vargas (FGV) no Rio de Janeiro, Fundação Getúlio Vargas em São Paulo e Universidade de São Paulo (USP). A seleção de apenas programas com conceitos 6 e 7 se justifica por representarem os cursos mais desenvolvidos no Brasil, com histórico mais longo, e qualidade verificada pelas agências de regulamentação. Consideramos apenas os graduados por doutorados em Administração de Empresas, não incluindo outras áreas como Administração Pública, Contabilidade ou Turismo, por opção de escopo e para evitar possíveis diferenças entre áreas disciplinares.

A segunda etapa envolveu a delimitação do horizonte temporal do estudo. A implicação desta delimitação reflete-se na amostragem de doutorados, que neste caso restringimos aos graduados do doutorado entre 2009 e 2012 (quatro anos). Esta escolha se justifica, pois até 2008 a avaliação da produção científica, como realizada pela Capes, dava considerável peso para participações em eventos e publicações em anais de congressos. Contudo, a partir de 2008, os congressos perderam seu valor de pontuação e a produção passou a ser contabilizada pelas publicações em periódicos com revisão pelos pares, seguindo as classificações Qualis/Capes. Importa ainda esclarecer que, para a classificação da produção científica dos doutorados (orientados), consideramos os dados de publicação a partir do ano anterior à defesa de tese até dois anos depois da defesa. Assim, por exemplo, para um doutor titulado em 2011, foram consideradas as produções publicadas em 2010, 2011, 2012 e 2013. Este período temporal é o que melhor representa o efeito da orientação na publicação científica do orientado. Considerar um horizonte mais abrangente seria passível de introduzir efeitos que confundiriam os resultados, como a integração em programas stricto sensu, redes de coautorias estabelecidas, etc. E, dado que a publicação de um artigo pode levar um ou dois anos após a submissão (ver Phelan, Ferreira, \& Salvador, 2002), consideram-se os artigos publicados após o terceiro ano do curso de doutorado até dois anos depois da defesa de tese (compreendendo, assim, pelo menos em parte, as publicações provenientes do trabalho de tese). A amostra termina nos doutores titulados em 2012, pois desta forma haveria dois anos após a titulação para análise das publicações (2013 e 2014). Os dados para este estudo foram coletados em 2015.

A terceira etapa consistiu na construção de uma base de dados com os nomes de cada um dos novos doutores que se formaram nas instituições escolhidas, dentro do horizonte temporal do estudo, e dos seus orientadores. Essas informações foram coletadas dos cadernos de indicadores CAPES, onde constam dados das teses de doutorado defendidas em cada programa de doutorado.

Finalmente, a quarta etapa consistiu no levantamento da produção científica dos doutores formados e seus respectivos orientadores. Esses dados foram coletados dos currículos Lattes; a etapa envolveu contagem de artigos e sua classificação usando a listagem Qualis de 2014. Especificamente, calculamos o número de publicações, classificamos os artigos em Qualis A1, A2, B1, B2, B3, B4 e B5, e calculamos o número de pontos Qualis correspondentes. Houve cinco casos onde o currículo Lattes do orientado não havia sido atualizado com os dados dos anos focais do estudo. Estes cinco casos foram excluídos da amostra, ficando com uma amostra final de 313 casos. Não houve casos de alunos sem currículos Lattes. A não atualização do currículo Lattes após dois anos de titulação do aluno pode indiciar o abandono da carreira acadêmica ou um abandono, ou desinteresse, pelo componente de pesquisa.

Outras informações, posteriormente incluídas nas regressões como variáveis de controle, também foram coletadas, como o ano de egresso do orientado e o número de publicações antes do horizonte 
temporal (ou seja, antes de o estudante entrar no doutorado e durante os primeiros 2 anos de doutorado). Esses dados foram coletados dos currículos Lattes e a classificação e codificação da produção científica foi feita para os professores orientadores e para os estudantes de doutorado orientados.

\section{Amostra}

A amostra final da pesquisa foi composta por 313 estudantes que se graduaram do doutorado entre 2009 a 2012. Estes 313 doutorados tiveram um total de 127 professores orientadores. A Tabela 1 apresenta alguns dados descritivos da amostra. Por exemplo, dos 313 orientados, 41 foram da FGV/RJ, 84 da FGV/SP, 32 da UFMG e 156 da USP. A tabela ainda revela a composição segundo o ano de titulação dos orientados doutorados. O programa doutoral que titulou mais doutores durante o período foi o da USP, com quase metade da amostra.

Tabela 1

Número de Orientados e Orientadores, por Programa, na Amostra

\begin{tabular}{lcccccc}
\hline Instituição & $\begin{array}{c}\text { N. de Professores } \\
\text { orientadores }\end{array}$ & $\begin{array}{c}\text { Estudantes } \\
\text { doutorados } \\
\text { em 2009 }\end{array}$ & $\begin{array}{c}\text { Estudantes } \\
\text { doutorados } \\
\text { em 2010 }\end{array}$ & $\begin{array}{c}\text { Estudantes } \\
\text { doutorados } \\
\text { em 2011 }\end{array}$ & $\begin{array}{c}\text { Estudantes } \\
\text { doutorados } \\
\text { em 2012 }\end{array}$ & $\begin{array}{c}\text { N. de estudantes } \\
\text { doutorados }\end{array}$ \\
\hline FGV/RJ & 18 & 11 & 8 & 7 & 15 & 41 \\
UFMG & 14 & 6 & 7 & 8 & 11 & 32 \\
FGV/SP & 36 & 14 & 18 & 27 & 25 & 84 \\
USP & 59 & 43 & 45 & 32 & 36 & 156 \\
\hline Total & 127 & 74 & 78 & 74 & 87 & 313 \\
\hline
\end{tabular}

Nota. Fonte: Calculado pelos autores com dados da pesquisa.

\section{Variáveis}

Utilizamos duas variáveis dependentes da produção científica dos recém-doutorados. Primeiro, a quantidade, ou número, de artigos publicados durante a janela de tempo de quatro anos definida entre 2 anos antes de terminar o doutorado e 2 anos depois. Esta foi mensurada como o número de artigos. Os dados foram coletados dos currículos Lattes dos orientados. A segunda forma de mensuração refere-se ao aspecto qualitativo da produção científica, que foi mensurado como a qualidade média das publicações do recém-doutorado. Para esta codificação, classificamos cada artigo publicado segundo os estratos Qualis e dividimos o número de pontos pelo número de artigos. Para calcular a qualidade média das publicações usamos os pontos Qualis dos artigos publicados, usando a métrica seguinte: $\mathrm{A} 1=100$, $\mathrm{A} 2=80, \mathrm{~B} 1=60, \mathrm{~B} 2=50, \mathrm{~B} 3=30, \mathrm{~B} 4=20, \mathrm{e} \mathrm{B} 5=10$ pontos.

\section{Variáveis independentes}

As variáveis independentes referem-se ao histórico de publicações dos professores orientadores. Assim, aferimos o número de publicações dos orientadores pelo somatório simples de todas as publicações de cada professor orientador até ao ano de titulação de cada um dos seus orientados. Os dados foram coletados do Lattes dos orientadores.

Também mensuramos a pontuação média das publicações do orientador, calculada dividindo a pontuação Qualis total pelo número de artigos publicados. Por fim, calculamos o número de artigos de topo publicados pelo professor orientador, seguindo a definição de Falaster, Ferreira e Serra (2016), de artigos de topo como os publicados em periódicos dos estratos A1 e A2. Adicionalmente, é importante ressaltar que os dados foram utilizados em relação a cada orientado com base no ano de 
titulação do orientado. Ou seja, para um orientado titulado em 2010, só foram consideradas as publicações do orientador até 2010 para o cálculo das regressões.

\section{Variáveis de controle}

Incluímos, ainda, variáveis de controle para melhor estimar os efeitos, ou potencial de impacto da orientação sobre o orientado doutorado. Introduzimos o ano de titulação do recém-doutor, dado que é possível que a produção científica dos graduados mais recentemente seja superior à dos anos anteriores, devido às mudanças institucionais realizadas pela CAPES. Utilizamos o ano de 2012 como ano base de comparação. Também inserimos, como controle, as publicações dos doutorados antes do horizonte temporal em análise - que designamos por produções anteriores, seguindo Paglis et al. (2006). Efetivamente, Paglis et al. (2006) propuseram que, pelo menos em parte, a futura produtividade de um pesquisador pode ser determinada pelas suas publicações anteriores ao doutorado, o que leva à necessidade de controlar quaisquer resultados pelo número de publicações anteriores ao doutorado. Neste caso, mensuramos apenas o volume de publicações, na forma de contagem do número de artigos. Esta inclusão justifica-se porque alguns doutorandos já acedem ao programa doutoral com um histórico substancial de publicações realizadas no mestrado ou que resultam dos trabalhos ou parceiras realizadas durante o mestrado. Esta variável controla, assim, o conhecimento e a competência prévios e distintos dos acumulados durante a realização do doutorado.

\section{Análise dos dados}

Este estudo utiliza uma abordagem quantitativa e, para o teste das hipóteses, os dados foram analisados com técnicas estatísticas multivariadas, de regressão linear múltipla. A regressão múltipla é indicada quando temos dados mensuráveis para variáveis dependentes e independentes (Hair, Black, Babin, \& Anderson, 2013) e buscamos algum nível de generalização de resultados para uma dada caraterização da amostra (Hair et al., 2013). Utilizar dados secundários é comum em pesquisas sobre o ensino superior e oferece resultados confiáveis quando o foco da amostra é individual, com dados por aluno (Thomas \& Heck, 2001).

Para evitar potenciais problemas de endogeneidade nos modelos de regressão - por erros de mensuração, autorregressão, variáveis omissas ou causalidade simultânea - tivemos alguns cuidados. Realizamos o estudo com dados secundários para evitar problemas de coleta, como sejam os de variância comum na coleta por questionário e os de mensuração das variáveis. O uso de dados secundários diminui consideravelmente os problemas de endogeneidade relacionados ao viés de métodos comuns (ver MacKenzie \& Podsakoff, 2012). Na análise não realizamos uma técnica longitudinal, na qual a produção científica num período t poderia estar altamente correlacionada com a produção em $t-1$. Utilizamos apenas a produção anterior do discente como variável de controle. Para evitar variáveis omissas incluímos o ano e a produção anterior como variáveis de controle, além da classificação dos programas doutorais. Para este efeito também restringimos o escopo da análise apenas a programas classificados como 6 e 7 pela CAPES. Ao restringir o período, restringimos também a possibilidade de variáveis omissas, como as mudanças na regulamentação que incidem sobre a avaliação dos pesquisadores e dos programas.

\section{Resultados}

A Figura 1 revela uma primeira análise descritiva dos resultados, evidenciando a média do número de artigos publicados por orientadores (esquerda) e estudantes (direita) durante o período de pesquisa, por estrato Qualis. Não surpreende que os orientadores tenham maior volume e qualidade de publicações, como seria de esperar. Mas é evidente a diferença de qualidade das publicações realizadas por orientadores e orientados quando fazemos uma comparação por estrato dos periódicos. Os estudantes têm maior concentração de publicações nos estratos entre A2 e B3. Em contraste, os orientadores tendem 
a publicar mais artigos em periódicos de estratos A2 e B1, com menor incidência nos restantes. De certa forma, esses resultados apontam uma tendência já esperada, visto que estudantes estão iniciando suas carreiras acadêmicas e tendem a publicar em periódicos de estratos um pouco mais baixos. Já os orientadores têm foco em estratos mais altos, porém não deixam de publicar em estratos medianos, possivelmente para ajudar estudantes em coautorias (Serra \& Ferreira, 2015) e ajudar revistas em fases iniciais.

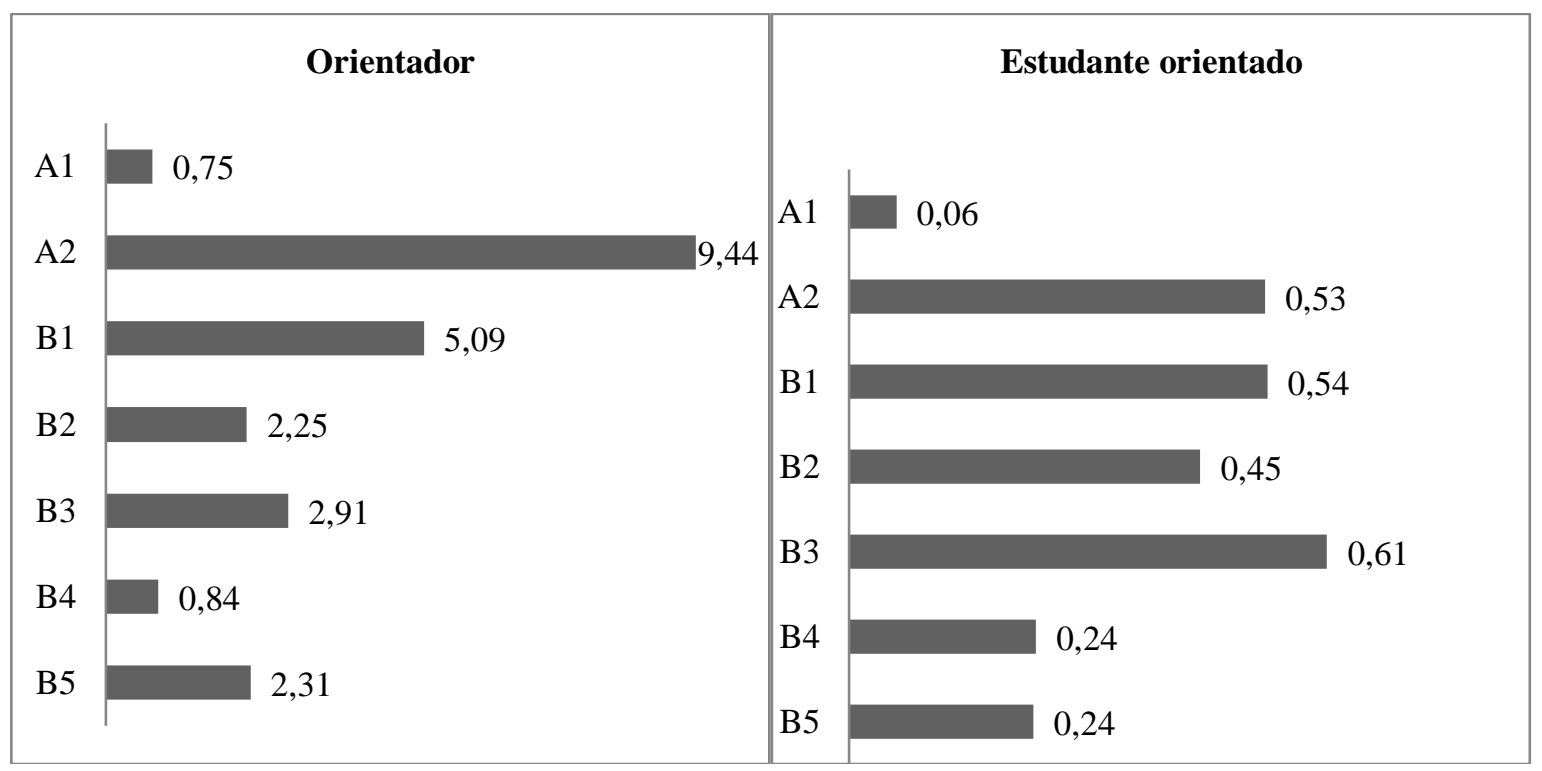

Figura 1. Médias de Produção de Orientadores e Orientados por Estrato

Os valores na figura são as médias de artigos publicados em periódicos em cada estrato Qualis dos orientadores, à esquerda, e dos orientados, à direita. Fonte: pelos autores com dados da pesquisa.

Talvez seja surpreendente que, na amostra, também existam orientadores e orientandos sem qualquer publicação. Em contraste, há orientandos com números bastante consideráveis de artigos publicados, chegando a 32 artigos nos anos focais da pesquisa. Evidências para esses altos níveis de produção também podem ser encontradas nos estudos de Falaster, Ferreira e Serra (2016) que analisaram o desempenho de publicações dos graduados em programas doutorais no período de 1998 a 2008.

Na Figura 2, os números totais de artigos publicados pelos professores orientadores (à esquerda) e estudantes orientados (à direita). Inclui-se uma variável NP que indica o número de elementos na amostra que não tiveram qualquer publicação durante os anos focais da pesquisa. É visível que os orientadores publicaram um número muito maior de artigos em periódicos no estrato A2 (1.119) do que em outros estratos. Publicaram 646 artigos em periódicos B1 e 95 artigos em periódicos no estrato A1. 


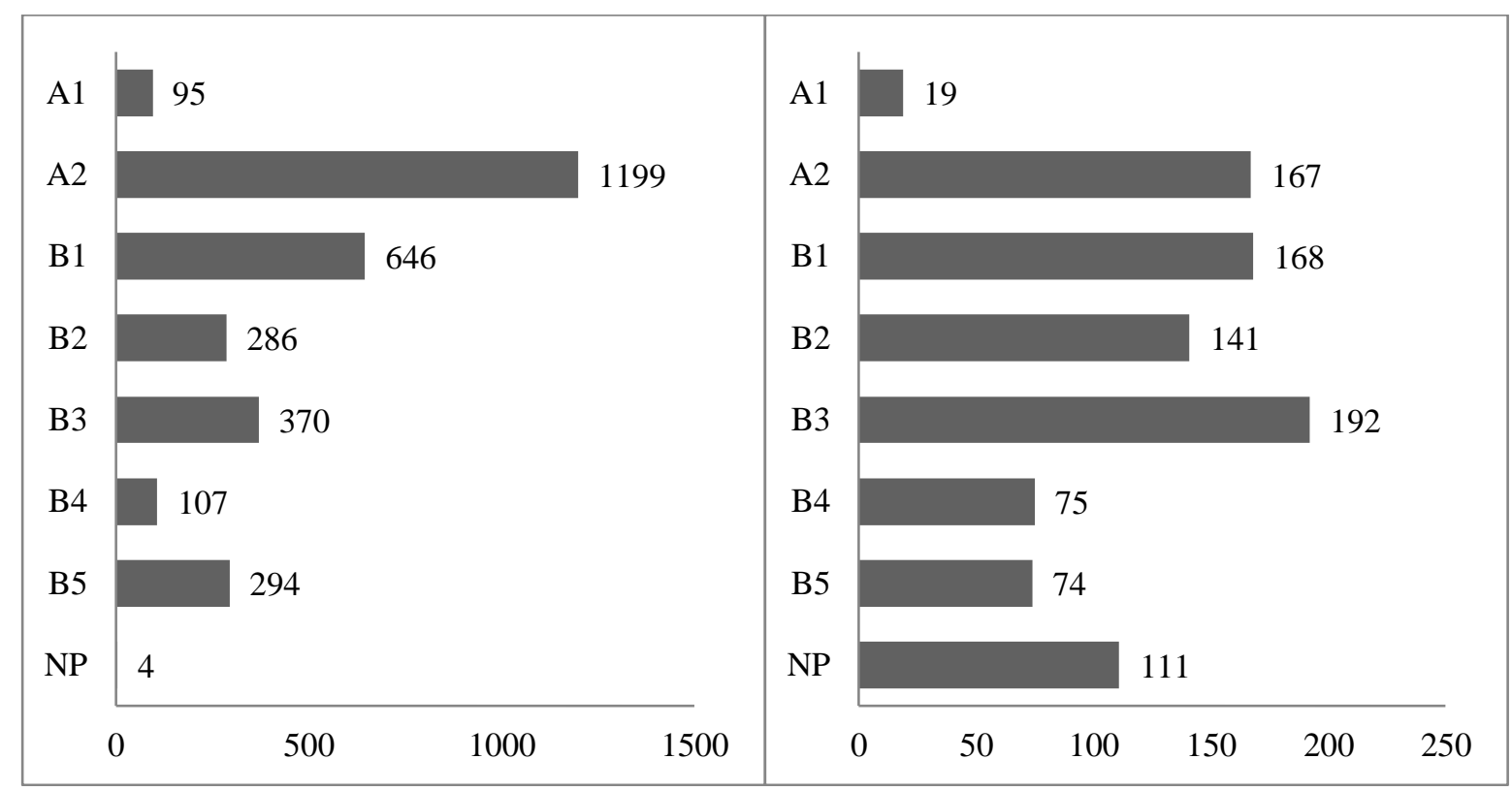

Figura 2. Volume da Produção Científica por Estrato e Número de Observações Sem Publicações Os valores referem-se ao número total de artigos publicados por orientadores, à esquerda, e orientados, à direita. NP - Número de orientadores (à esquerda) e orientados (à direita) que não obtiveram publicações indexadas no Qualis durante os anos focais. Fonte: pelos autores com dados da pesquisa.

Entre o volume de publicações dos estudantes orientados, observamos equilíbrio entre os estratos das publicações. Os orientados tiveram publicações de nível B3 (192), B2 (168) e B1 (167), demonstrando uma diferença muito grande entre focos de publicação dos orientadores e dos orientandos, mesmo salvaguardadas as proporções dos números totais de artigos publicados. Também é interessante notar estudantes e orientadores que não publicaram qualquer artigo durante os anos de pesquisa. 111 recém-doutores não tiveram publicação alguma durante os quatro anos da pesquisa - dois anos antes de terminar o doutorado e dois depois do término -, o que representa 35,46\% da amostra (ou mais de um terço). Isto pode caracterizar a inabilidade de publicar até mesmo os artigos provenientes de suas teses. Já entre os professores orientadores, apenas quatro não tiveram qualquer publicação.

A Tabela 2, a seguir, apresenta elementos descritivos (mínimo, máximo, média e desvio padrão) e as correlações entre as variáveis usadas no estudo. As correlações são definidas por Hair, Black, Babin e Anderson (2013) como as associações das variâncias das variáveis, que podem indicar relação direta (quando positivas) e relação inversa (quando negativas). As correlações são, como seria de esperar, mais altas entre o número de artigos publicados e a qualidade média das publicações do orientador. Para analisar eventuais situações de multicolinearidade, realizamos um diagnóstico de colinearidade recorrendo ao Variance Inflation Factor (VIF). Os resultados mostram que não há problema de colinearidade entre as variáveis, com VIF inferior a 2,3, ainda dentro dos limites adequados (Hair et al., 2013). 
Tabela 2

\section{Descritivos e Correlações}

\begin{tabular}{|c|c|c|c|c|c|c|c|c|c|c|c|c|}
\hline & Mín. & Máx. & Média & $\begin{array}{l}\text { Desv. } \\
\text { pad. }\end{array}$ & 1 & 2 & 3 & 4 & 5 & 6 & 7 & 8 \\
\hline 1. Número de publicações dos orientados & 0 & 32 & 3,18 & 4,66 & 1,000 & & & & & & & \\
\hline 2. Qualidade média dos artigos do orientados & 0 & 100 & 26,80 & 27,18 & $0,697^{* *}$ & 1,000 & & & & & & \\
\hline 3. Produção anterior dos orientados & 0 & 66 & 3,25 & 5,38 & $0,506^{* *}$ & $0,271^{* *}$ & 1,000 & & & & & \\
\hline 4. Ano 2009 & 0 & 1 & 0,24 & 0,43 & $0,118^{*}$ & $0,158^{* *}$ & $-0,029$ & 1,000 & & & & \\
\hline 5. Ano 2010 & 0 & 1 & 0,25 & 0,43 & 0,006 & $-0,012$ & $0,112^{*}$ & $-0,319^{* *}$ & 1,000 & & & \\
\hline 6. Ano 2011 & 0 & 1 & 0,24 & 0,43 & $-0,020$ & $-0,009$ & $-0,028$ & $-0,308^{* *}$ & $-0,319^{* *}$ & 1,000 & & \\
\hline 7. Qualidade média dos artigos do professor orientador & 0 & 80 & 40,12 & 14,50 & 0,045 & $0,125^{*}$ & 0,057 & $-0,137^{*}$ & $-0,094$ & 0,088 & 1,000 & \\
\hline 8. Quantidade de artigos do professor orientador & 0 & 143 & 31,78 & 20,71 & $0,122^{*}$ & $0,160^{* *}$ & 0,070 & $-0,032$ & $-0,032$ & 0,011 & $-0,092$ & 1,000 \\
\hline $\begin{array}{l}\text { 9. Número de artigos de topo (A1 e A2) do professor } \\
\text { orientador }\end{array}$ & 0 & 37 & 6,72 & 7,88 & $0,113^{*}$ & $0,171^{* *}$ & 0,029 & $0,167^{* *}$ & $0,271^{* *}$ & $0,322^{* *}$ & $0,156^{* *}$ & $0,352^{* *}$ \\
\hline
\end{tabular}

Nota. Fonte: Dados da pesquisa.

* sig a $p<0,05$ ( 2 extremidades); ** Sig. a $p<0,01$ ( 2 extremidades). 
As Tabelas 3 e 4 apresentam os resultados das regressões. Na Tabela 3 testamos as hipóteses tendo como variável dependente a quantidade, ou o número, de artigos publicados pelo orientado durante os anos focais. O modelo 1 inclui apenas as variáveis de controle. Os modelos 2 e 3 testam as hipóteses. O modelo 4 é o modelo completo.

Tabela 3

Modelos de Regressão para a Quantidade de Publicação dos Orientados

\begin{tabular}{lcccc}
\hline & Modelo 1 & Modelo 2 & Modelo 3 & Modelo 4 \\
\hline Número de artigos do orientador & & 0,047 & & 0,071 \\
Qualidade média da produção do orientador & & & 0,037 & 0,054 \\
Ano 2009 & $-0,006$ & $-0,002$ & 0,001 & 0,028 \\
Ano 2010 & $-0,041$ & $-0,038$ & $-0,036$ & $-0,007$ \\
Ano 2011 & $-0,038$ & $-0,037$ & $-0,037$ & $-0,010$ \\
Publicações anteriores ao doutorado & $0,542^{* * *}$ & $0,538^{* * *}$ & $0,540^{* * *}$ & $0,536^{* * *}$ \\
\cline { 2 - 5 } p-valor da regressão & 0,000 & 0,000 & 0,000 & 0,000 \\
$\mathrm{R}^{2}$ ajustado & 0,286 & 0,286 & 0,285 & 0,284 \\
Soma dos quadrados & 2012 & 2026 & 2021 & 2043 \\
$\mathrm{~N}$ & 313 & 313 & 313 & 313 \\
\hline
\end{tabular}

Nota. A variável dependente é o número de artigos publicados pelos orientados. Fonte: Com dados da pesquisa.

$*$ sig a $\mathrm{p}<0,05 ; * * \operatorname{sig}$ a $\mathrm{p}<0,01 ; * * *$ sig a $\mathrm{p}<0,001$.

Tabela 4

Modelos de Regressão para a Qualidade Média da Publicação dos Orientados

\begin{tabular}{lccccc}
\hline & Modelo 1 & Modelo 2 & Modelo 3 & Modelo 4 & Modelo 5 \\
\hline $\begin{array}{l}\text { Número de artigos do orientador } \\
\text { Qualidade média da produção do orientador }\end{array}$ & & $0,186^{* * *}$ & & & $0,234^{* * *}$ \\
Artigos de topo (A1, A2) do orientador & & & $0,161^{* *}$ & & $0,199^{* * *}$ \\
Ano 2009 & $0,180^{* *}$ & 0,196 & $0,209^{* *}$ & $0,123+$ & $0,267^{* * *}$ \\
Ano 2010 & 0,055 & $0,068^{* *}$ & 0,077 & $-0,013$ & $0,138+$ \\
Ano 2011 & 0,072 & 0,075 & 0,077 & $-0,008$ & 0,127 \\
Publicações anteriores ao doutorado & $0,165^{* *}$ & $0,148^{* *}$ & $0,155^{* *}$ & $0,156^{* *}$ & $0,136^{*}$ \\
p-valor da regressão & 0,002 & 0,000 & 0,000 & 0,000 & 0,000 \\
R ajustado & 0,042 & 0,073 & 0,065 & 0,054 & 0,100 \\
Soma dos quadrados & 12575 & 20475 & 18404 & 16052 & 27697 \\
N & 313 & 313 & 313 & 313 & 313 \\
\hline
\end{tabular}

Nota. A variável dependente é a Qualidade média dos artigos publicados pelo orientado aferida pelos Qualis dos periódicos. Periódicos foram classificados em A1 e A2 com base no Qualis em vigor em 2014. Fonte: Dados da pesquisa.

$* \operatorname{sig}$ a $\mathrm{p}<0,05 ; * * \operatorname{sig}$ a $\mathrm{p}<0,01 ; * * * \operatorname{sig}$ a $\mathrm{p}<0,001$.

A hipótese 1 propõe que o número de publicações dos recém-doutorados orientados está positivamente relacionado com o volume e a qualidade das publicações do professor orientador. O teste estatístico da hipótese 1 , propondo uma relação positiva entre a qualidade (modelo 2) e volume (modelo 
3) de artigos do orientador na quantidade de artigos publicados pelo orientado, não permite confirmar uma influência significante da competência do orientador na produção do orientado. Ou seja, os resultados mostram que o volume de publicações dos orientados não parece ser influenciado pelo registro de publicações cientificas do orientador. É de salientar que, entre as variáveis de controle, o histórico anterior do orientado tem coeficientes altos e significantes nas regressões, denotando que há, efetivamente, e como seria de esperar, um não negligenciável elemento específico ao indivíduo. Pode ser a experiência pessoal do estudante, a qualidade da sua formação anterior, a motivação individual para pesquisar e publicar, ou mesmo características intrínsecas que não são objeto deste estudo, por estarem fora do escopo da pesquisa, mas que merecem pesquisa futura.

Na Tabela 4 testamos as hipóteses 2 e 3 . No modelo 1 incluímos apenas as variáveis de controle. A hipótese 2 sugere uma associação positiva entre a qualidade das publicações dos recém-doutorados orientados e o volume e qualidade das publicações do professor orientador. No modelo 2, testamos o efeito do volume (ou número) de artigos do orientador na qualidade média da produção do orientado, confirmando-se um efeito positivo e significante $(\beta=0,186, p<0,001)$. No modelo 3 testamos o efeito da qualidade média da produção do orientador na qualidade média da produção do estudante, verificandose um efeito positivo e significante $(\beta=0,161, p<0,010)$, confirmando que há uma associação positiva entre a qualidade de artigos produzida pelo orientador e a qualidade média da produção do orientado.

No modelo 4, testamos a hipótese 3 propondo que a qualidade das publicações dos recémdoutorados orientados está positivamente relacionada com o número de artigos de mais alta qualidade (publicados em periódicos do topo do ranking - A1 e A2) pelo professor orientador. Um coeficiente positivo e significante $(\beta=0,144, p<0,050)$ confirma a hipótese 3 sobre o efeito na qualidade média dos artigos do orientado.

Em suma, os resultados mostram que a competência de publicação em qualidade dos estudantes de doutorado é melhorada quando trabalham com orientadores com maior competência de publicação (ou seja, de capacidade científica aferida pelo histórico de publicações). Os resultados confirmam que a competência do orientador é um preditor significante, seja esta competência avaliada pelo histórico de número de artigos, de qualidade média das publicações ou de orientação para periódicos de estratos mais altos. Em suma, professores orientadores que publicam mais, que publicam em periódicos classificados em estratos superiores, impactam positivamente os seus orientandos de forma a melhorar a qualidade média de suas publicações.

\section{Análise complementar}

Por fim, realizamos uma análise complementar de natureza qualitativa e descritiva para analisar variações. Especificamente, buscamos identificar, na amostra, casos de orientadores com orientados altamente produtivos e outros pouco produtivos, além de casos em que o orientador é muito produtivo, mas não os seus orientandos. Na Tabela 5 , mostramos as produções, por estratos, dos orientadores e, logo abaixo, as produções de seus orientados durante os anos focais de estudo. Em geral, os dados apontaram que há diferenças assinaláveis, revelando, como afirmamos, que outras variáveis, para além do orientador, necessitam ser adicionadas em pesquisas futuras. Os dados também mostram que ter orientadores produtivos não é um preditor preciso das publicações do orientado, já que alguns orientados têm baixo nível de produção mesmo tendo orientadores muito produtivos. No entanto, todos os estudantes que obtiveram um grande número de artigos (assim como artigos em periódicos em estratos mais altos) também tiveram orientadores com níveis relativamente altos de produção científica. Então, ter um orientador muito produtivo não garante alta produtividade, mas para ter alta produtividade é necessário ter um orientador, no mínimo, bastante produtivo. Por outro lado, todos os orientandos de professores de produção zero tiveram níveis extremamente baixos de produção. Ou seja, encontramos reforço, pelo menos parcial, de que o orientador contribui para melhorar a produção do orientado. 
Tabela 5

Análise Complementar: Observação Individualizada da Produção de Orientadores e Orientados

\begin{tabular}{lccccccc}
\hline & A1 & A2 & B1 & B2 & B3 & B4 & B5 \\
\hline Orientador A & 1 & 37 & 22 & 10 & 11 & 3 & 1 \\
Estudante A1 & 0 & 1 & 1 & 1 & 0 & 0 & 0 \\
Estudante A2 & 0 & 10 & 5 & 10 & 3 & 2 & 2 \\
Estudante A3 & 0 & 2 & 0 & 0 & 0 & 0 & 0 \\
Estudante A4 & 0 & 0 & 0 & 0 & 0 & 0 & 0 \\
\hline Orientador B & 0 & 53 & 8 & 2 & 5 & 0 & 5 \\
Estudante B1 & 0 & 1 & 0 & 0 & 0 & 0 & 0 \\
Estudante B2 & 0 & 1 & 0 & 0 & 0 & 0 & 0 \\
\hline Orientador C, D, E, e F. & 0 & 7 & 27 & 18 & 15 & 0 & 3 \\
Estudante C1, D1, E1 e F1 & 0 & 0 & 0 & 1 & 0 & 0 & 0 \\
\hline Orientador E & 1 & 37 & 22 & 10 & 11 & 3 & 1 \\
Estudante E1 & 0 & 10 & 5 & 10 & 3 & 2 & 2 \\
\hline Orientador F & 1 & 6 & 9 & 1 & 0 & 4 & 3 \\
Estudante F1 & 1 & 4 & 1 & 3 & 5 & 1 & 0 \\
\hline Orientador G & 0 & 6 & 5 & 0 & 1 & 0 & 1 \\
Estudante G1 & 0 & 3 & 4 & 1 & 6 & 2 & 7 \\
\hline
\end{tabular}

Nota. Fonte: pelos autores com dados da pesquisa.

\section{Discussão e Considerações Finais}

Neste artigo, investigamos a relação entre a competência científica de publicação de artigos do orientador e do seu orientando. Especificamente, analisamos o histórico de publicações do professor orientador e a publicação de artigos por seu orientando, para traçar uma relação entre a qualidade e quantidade de publicações do orientador e a qualidade e quantidade de publicações do orientando. Assim, exploramos o conhecimento sobre os resultados da relação entre orientador e orientando, partindo das evidências de estudos existentes, como Punyanunt-Carter e Wrench (2008), Paglis et al. (2006) e Hilmer e Hilmer (2009), que já apontavam a possibilidade desta relação, mas sem testá-la empiricamente. Certamente que a competência científica se refere a muito mais do que apenas publicações de artigos e é mais do que a publicação em periódicos classificados de estratos. No entanto, esta é a mensuração que é mais comumente realizada, descurando-se, talvez infelizmente, outras atividades, inclusive de ensino, dos professores pesquisadores. As pressões institucionais e organizacionais (dos programas ou universidades) têm conduzido ao foco nas publicações e, especialmente mais recentemente, às publicações de qualidade (Ferreira, 2015; Nascimento, 2010).

Assim, o presente estudo faz uma contribuição para a literatura sobre a formação dos pesquisadores, notavelmente durante os seus percursos de doutorado (Falaster, Ferreira, \& Serra, 2016; Sheldon et al., 2015), e sobre a relação entre orientador e orientado (Paglis et al., 2006), ao estabelecer uma relação entre a produção científica do orientador com a dos seus estudantes de doutorado (Hilmer \& Hilmer, 2009). Nossos resultados expandem trabalhos como o de Williamson e Cable (2003), que evidenciaram que há uma relação entre a produção do orientador e do orientado, mas não investigaram os efeitos diretos entre qualidade e quantidade de artigos. Há, também, implicações de espectro mais prático que emergem do estudo. Para os programas doutorais que são avaliados pela CAPES segundo 
métricas que usam a produção científica, este estudo demonstra uma das vertentes do processo de orientação dos estudantes de doutorado. Especificamente, analisando os atributos da produção científica dos professores de stricto sensu que influenciam a futura produção científica de seus estudantes. Dessa forma, as direções dos programas doutorais podem melhor compreender um dos fatores que formam a produção científica discente e como a produção dos seus docentes pode influenciar a qualidade e quantidade de publicações dos alunos. Esse conhecimento pode ser especialmente relevante para criar mecanismos de incentivos a publicações de impacto, mas, também, para analisar as contratações de novos docentes face às necessidades específicas dos programas.

Os resultados permitem tirar conclusões sobre a relação entre a produção científica do orientador e a do orientado. Especificamente, os resultados explicam razoavelmente uma forte relação entre o histórico de publicações do orientador com a qualidade média de publicações do recém-doutor. Os efeitos mais evidentes que identificamos é que número de artigos publicados pelo orientador, a qualidade dos artigos publicados pelo orientador e o número de artigos de topo do ranking publicados pelo orientador não têm efeito algum sobre a quantidade de artigos do orientando. A produção do orientador tem efeitos diretos sobre a qualidade e não a quantidade de artigos do orientando. Em contraste, o número de artigos já publicados pelo professor orientador em sua carreira assim como a qualidade média dos artigos publicados têm influências positivas e significantes sobre a qualidade média da publicação do orientando. A quantidade de artigos de topo do ranking publicados pelo orientador também apresentou uma relação positiva com a qualidade de artigos do orientando.

Esses resultados corroboram os achados de Williamson e Cable (2003) quanto a haver relação entre a produção do orientando e do orientado, além de contribuir com Punyanunt-Carter e Wrench (2008) quanto à forte relação entre o orientador e o sucesso futuro do seu orientando. Nossos resultados também apoiam parcialmente os estudos de Paglis et al. (2006), que evidenciaram que uma orientação de qualidade poderia determinar o sucesso futuro do orientando, pois em nosso trabalho não pudemos mensurar a qualidade da orientação em si enquanto processo multidimensional, mas pudemos evidenciar os efeitos da habilidade do orientador em publicar. Por fim, colaboramos também com os resultados de Hilmer e Hilmer (2009) de forma a apontar para a disparidade entre discentes do mesmo programa que pode estar ligada ao efeito do orientador na produção discente.

Os resultados de nosso estudo apresentam algumas implicações positivas contra o produtivismo acadêmico, indicando que os orientadores costumam influenciar na qualidade das publicações e não na quantidade, desafiando, assim, a lógica de que os professores preparariam seus alunos para publicar grandes quantidades sem observar a qualidade. Os resultados parecem trazer alguma sustentação a comportamentos diferenciados e apoiam, pelo menos em parte, as críticas ao produtivismo que vigoram. Ou seja, demonstram que o orientador que tem mais experiência com publicações e publicações de maior qualidade influencia seu orientando a ter publicações de maior qualidade, mas não em volume. $\mathrm{O}$ argumento de produtivismo acadêmico indicaria uma supervalorização da quantidade de publicações em detrimento da qualidade, indicando, dessa maneira, a produção de artigos científicos com o - talvez único - intuito de cumprir quesitos de pontuação acadêmica (Bertero, Alcadipani, Cabral, Faria, \& Rossoni, 2013), e teria raízes no sistema institucional (Alcadipani, 2011), com o propósito de atingir as metas individuais dos programas e dos pesquisadores. Porém, a necessidade de publicar poderia colocar a pressão para aumentar o volume de publicações à frente do esforço pela qualidade (Miller, Taylor, \& Bedeian, 2011; Patrus et al., 2015). Os nossos resultados mostram que orientadores que produzem mais (maior número de publicações) e com maior qualidade (i.e., em periódicos de estratos Qualis mais altos) acabam por impactar a qualidade da produção de seus orientados. No entanto, numa lógica mais produtivista - aferida apenas tendo como referência o volume de produção - demonstrou-se que a quantidade de publicações do estudante não é influenciada pela quantidade ou qualidade das publicações do orientador. 


\section{Desenvolvendo linhas de pesquisas futuras}

Há várias perspectivas complementares que pesquisas futuras poderão abordar. Primeiro, diversos outros aspectos, além do orientador, poderão impactar a competência de publicação dos recém-doutores. Assim, importará analisar, inclusive, determinantes mais individuais e prévios ao ingresso no programa doutoral, tal como a experiência passada em publicações (Paglis et al., 2006). No Brasil, o mestrado acadêmico é um grau com forte vocação para a preparação para a pesquisa, estabelecendo as fundações teóricas e de metodologia de trabalho que serão aprofundadas durante o doutorado. A valorização do mestrado na realidade brasileira contrasta com a negligência que o mestrado, enquanto grau acadêmico, sofre em outros países europeus e nos Estados Unidos (Conrad, Duren, \& Haworth, 1998). Em nosso estudo, usamos as publicações anteriores como variável de controle, mas importará explorar melhor o leque de competências adquiridas anteriormente como preditor da capacidade de publicar (Conley \& Önder, 2014). Haverá potencialmente, ainda, fatores individuais, como a proficiência em inglês do pesquisador e as suas competências em abordagens quantitativas e estatísticas que são determinantes para publicar em periódicos internacionais com impacto (Falaster \& Ferreira, no prelo; Man, Weinkauf, Tsang, \& Sin, 2004; Phelan et al., 2002). Dessa maneira, as evidências encontradas neste artigo ajudam a esclarecer parte da discussão sobre a produção discente, mas não explicam o fenômeno por completo, deixando a necessidade de estudos adicionais para analisar as diferentes facetas da publicação e das competências, ou falta de competências (Serra et al., 2008), para publicar.

A publicação do discente e a relação da publicação deste com a do seu orientador também podem ser influenciadas por objetivos pessoais. Nem todos os estudantes de doutorado pretendem seguir carreira acadêmica, pois, conforme visto em Falaster, Ferreira e Serra (2016), nem todos os egressos de programas de stricto sensu publicaram algum artigo depois de sua titulação, e alguns doutores egressos nem sequer possuem currículos no sistema Lattes. Parte desses aparentes abandonos pode representar casos de estrangeiros que regressam aos seus países, mas, em muitos casos, também serão doutores que prosseguem para outros percursos profissionais fora da academia.

Uma análise que é relevante ser feita e que tem distinguido a formação de doutorado no Brasil em relação à dos Estados Unidos ou mesmo da Europa é o nível de profissionalização do estudante. Por exemplo, um estudante de doutorado na Dinamarca recebe um salário e é considerado funcionário da universidade até o final dos seus estudos. Espera-se, assim, dedicação integral. A realidade brasileira é bem distinta, com os estudos de doutorado a acumularem para além dos empregos full time dos estudantes. Enquanto alguns estudantes de doutorado podem se dedicar à pesquisa com bolsas de tempo integral de dedicação, outros alunos precisam equilibrar o doutoramento à sua rotina de professor em universidades e até mesmo como profissionais no mercado. Também os valores das bolsas não são usualmente suficientes nem para cobrir as despesas correntes da vida dos estudantes. Ou seja, as práticas organizacionais e nacionais de fomento à pesquisa criam discrepâncias nos históricos de publicação científica entre países, mas também criam discrepâncias entre as publicações de discentes orientados pelo mesmo professor, no mesmo ano, na mesma instituição. Nesse sentido, é razoável assumir que estudantes que tenham mais tempo e motivação para se dedicar à pesquisa poderão absorver melhor o conhecimento fornecido pelo orientador, com mais tempo dedicado, e consigam, assim, um maior número e melhor qualidade de publicações ao final de seu doutorado. Estudos futuros poderiam não apenas utilizar abordagens quantitativas, mas também empregar abordagens qualitativas para investigar os efeitos dessas variáveis na relação de produção do professor orientador com o aluno. Estudos qualitativos podem evidenciar relações sobre as dinâmicas da formação do pesquisador. Métodos como a análise de discurso de doutores de alto número de publicações, sobre suas orientações, poderiam trazer novas evidências ao tema, tal como poderiam trazer novas informações concernentes a estudantes e ao seu aprendizado na relação de orientação.

Neste estudo não analisamos as contribuições efetivas de orientadores e orientados para cada artigo publicado, também não examinamos as publicações realizadas independentemente pelos orientandos e pelos orientadores. Assim, estudos futuros podem debruçar-se sobre a análise das contribuições relativas de cada coautor nos artigos (Smith, 1994). Estas são questões relacionadas às coautorias, mas que são extensíveis à análise de aspectos como até que ponto a propensão a realizar 
pesquisa e publicar em conjunto com o orientador determina a produtividade do estudante. Ou seja, até que ponto se realiza um aprendizado pelo estudante. Assim, estudos futuros podem trazer o número de coautorias entre orientador e orientando como uma variável moderadora da relação entre produção do orientador e produção do orientando.

Outras variáveis que possivelmente alteram essa relação podem estar ligadas ao professor orientador. Alguns professores podem ter menor disponibilidade de tempo, ou até mesmo menor interesse em orientar estudantes, o que pode ser decorrente de suas posições e afazeres nos programas. É questionável se apenas uma alta produção ou produção de alta qualidade do professor teria algum efeito sobre o orientando caso o professor não esteja disponível e apto a auxiliar e ensinar seu estudante com as publicações. De modo similar, seria relevante explorar os objetivos e a forma de trabalho dos professores orientadores, dado que esses fatores previsivelmente influenciarão o aprendizado do estudante. Por exemplo, se os professores orientadores publicam pesquisas independentemente da produção de seus orientandos, isso demonstraria que estes ainda vão ao campo, escrevem, buscam novos objetos de pesquisa e não apenas se acomodam nas pesquisas dos mestrandos e doutorandos. Ou, em contraponto, se os professores de stricto sensu trabalham sozinhos ou com outros professores, isso implicaria menor aprendizado do orientado com o orientador porque os orientadores teriam menos tempo ou interesse para trabalhar com seus alunos.

\section{Limitações e pesquisa adicional}

Este estudo tem limitações. Primeiro, apontam-se as limitações nos dados, pois, utilizando-se dados secundários é impossível uma efetiva mensuração das relações estabelecidas entre os orientadores e orientados nos programas de doutorado. Professores podem ter mais afinidade de trabalho com um de seus orientandos e menor com outro. Outro fator seria a qualidade da orientação, visto que nem todos os professores orientadores que têm habilidades para publicar teriam necessariamente habilidades didáticas para lidar com seus orientandos (Hilmer \& Hilmer, 2009). Pesquisas futuras podem analisar os efeitos da qualidade da orientação em si mesma, e talvez do estilo de orientação (Punyanunt-Carter \& Wrench, 2008), nessa relação entre a produção do orientador e a do seu orientando. Essas pesquisas teriam como contribuição um ponto de vista mais didático sobre as relações entre a produção do orientador e do orientado.

Neste estudo não buscamos compreender se o estilo de orientação e o tipo de relação estabelecida entre orientador e orientado teriam um impacto na relação proposta. Este teste não é viável com dados secundários, mas pode ser analisado com dados coletados por questionário avaliando os dois aspectos. $\mathrm{O}$ fato é que a experiência e aprendizado durante o doutorado podem ser influenciados pela relação que o estudante tem com seu orientador (Brockman et al., 2010). Como em todas as relações, os interesses de ambas as partes podem não ser congruentes e o conflito pode emergir nas relações orientadororientado (Brockman et al., 2010; Punyanunt-Carter \& Wrench, 2008). Em alguns casos, a falta de credibilidade e agressões verbais podem potencialmente pôr em risco todos os benefícios positivos de orientação (Punyanunt-Carter \& Wrench, 2008). Em outros casos, a relação pode trazer benefícios para ambos, tanto orientador quanto orientado (Paglis et al., 2006). Entender como o estilo de orientação e a relação estabelecida impactam os indicadores de produção científica pode ser especialmente relevante para todos os envolvidos, inclusive para os diretores de programas doutorais que podem implementar ações para promover as práticas mais adequadas aos objetivos.

\section{Considerações finais}

Este estudo investigou os efeitos da produção do orientador na produção dos seus orientados em programas brasileiros de Administração. Neste artigo, obtivemos indícios de que o histórico de produção do orientador influenciará positivamente a qualidade (i.e., publicação em periódicos de estratos Qualis mais altos), mas não a quantidade de artigos produzidos pelo orientado. Os resultados também lançam questionamentos sobre se é necessário ter um orientador altamente produtivo para ser um estudante altamente produtivo, enquanto um orientador muito produtivo não necessariamente garantirá que seus orientados sejam altamente produtivos. Especificamente, nosso estudo contribui para a academia por 
permitir a análise da relação entre orientação e produção do orientado, apesar de não explicar todo o fenômeno. A orientação é uma parte indissociável da formação do pesquisador e, compreendendo melhor os efeitos decorrentes da orientação, é possível melhorar a formação dos pesquisadores brasileiros e, assim, melhorar a pesquisa em administração decorrente dos programas doutorais do país.

\section{Agradecimentos}

Agradecemos o apoio financeiro do Conselho Nacional de Desenvolvimento Científico e Tecnológico (CNPq, processo $\mathrm{n}^{\circ}$ 445928/2014-0) para a realização da pesquisa.

\section{Referências}

Bertero, C. O., Alcadipani, R., Cabral, S., Faria, A., \& Rossoni, L. (2013). Os desafios da produção de conhecimento em administração no Brasil. Cadernos EBAPE.BR, 11(1), 181-196. http://dx.doi.org/10.1590/S1679-39512013000100012

Brockman, J., Nunez, A., \& Basu, A. (2010). Effectiveness of a conflict resolution training program in changing graduate students style of managing conflict with their faculty advisors. Innovative Higher Education, 35(4), 277-293. http://dx.doi.org/10.1007/s10755-010-9142-z

Conley, J., \& Önder, A. (2014). The research productivity of new PhDs in economics: the surprisingly high non-success of the successful. The Journal of Economic Perspectives, 28(3), 205-215. http://dx.doi.org/10.1257/jep.28.3.205

Conrad, C., Duren, K., \& Haworth, J. (1998). Students' perspectives on their master's degree experiences: disturbing the conventional wisdom. New Directions for Higher Education, 101(1), 65-76. http://dx.doi.org/10.1002/he.10106

Falaster, C., \& Ferreira, M. (no prelo). What drives publishing in top management journals: an analysis of language, quantitative competency and financial support. International Journal of Bibliometrics in Business and Management. Retrieved from http://www.inderscience.com/info/ingeneral/forthcoming.php?jcode=ijbbm. 1-19

Falaster, C., Ferreira, M., \& Canela, R. (2016). Motivos de rejeição dos artigos nos periódicos de administração. Organizações \& Sociedade, 23(77), 285-306. http://dx.doi.org/10.1590/19849230776

Falaster, C., Ferreira, M., \& Serra, F. (2016). The research productivity of new Brazilian PhDs in management: a few "star" performers outshine a mass of low performers. Management Research: Journal of Iberoamerican Academy of Management, 14(1), 60-84. http://dx.doi.org/10.1108/MRJIAM-11-2015-0619

Ferreira, M. (2013). O processo editorial: da submissão à rejeição (ou aceite). Revista Ibero-Americana de Estratégia, 12(3), 1-11. http://dx.doi.org/10.5585/riae.v12i3.2042

Ferreira, M. (2015). Periódicos e rankings de periódicos em administração. Revista Pensamento Contemporâneo em Administração, 9(2), 1-16. http://dx.doi.org/10.12712/rpca.v9i2.502

Ferreira, M., Canela, R., \& Pinto, C. (2014). O processo editorial nos periódicos e sugestões para a $\begin{array}{llllll}\text { publicação. Revista de Gestão } e \text { Secretariado, } & 5(2), & 1-22 .\end{array}$ http://dx.doi.org/10.7769/gesec.v5i2.307 
Ferreira, M., \& Falaster, C. (2016). Uma análise comparativa dos fatores de rejeição nos periódicos de diferentes estratos de administração. Revista de Administração Contemporânea, 20(4), 1-22. Recuperado de http://www.scielo.br/pdf/rac/v20n4/1982-7849-rac-20-4-0412.pdf. http://dx.doi.org/10.1590/1982-7849rac2016140144

Galbraith, Q., Smart, E., Smith, S., \& Reed, M. (2014). Who publishes in top-tier library science journals? An analysis by faculty status and tenure. College \& Research Libraries, 75(5), 724-735. http://dx.doi.org/10.5860/crl.75.5.724

Goldstein, E. (1979). Effect of same-sex and cross-sex role models on the subsequent academic productivity of scholars. American Psychologist, 34(5), 407-410. http://dx.doi.org/10.1037/0003066X.34.5.407

Hair, J. F., Jr., Black, W. C., Babin, B. J., \& Anderson, R. E. (2013). Multivariate data analysis (7th ed.). Harlow: Pearson Education Limited.

Harzing, A. (2010). The publish or perish book. Melbourne: Tarma Software Research.

Hilmer, M., \& Hilmer, C. (2009). Fishes, ponds, and productivity: student-advisor matching and early career publishing success for economics PhDs. Economic Inquiry, 47(2), 290-303. http://dx.doi.org/10.1111/j.1465-7295.2007.00108.x

Hotard, D., Tanner, J., \& Manakyan, H. (1996). Management faculty ratings of journal quality: the factors and the journals. Southern Business Review, 22(1), 8-20. http://dx.doi.org/10.1177/014920630002600505

Leite, G. A., Filho, \& Martins, G. de A. (2006). Relação orientador-orientando e suas influências na elaboração de teses e dissertações [Edição Especial]. Revista de Administração de Empresas, 46, 99-109. http://dx.doi.org/10.1590/S0034-75902006000500008

Maccari, E. A., Rodrigues, L. C., Alessio, E. M., \& Quoniam, L. C. (2011). Sistema de avaliação da pós-graduação da Capes: pesquisa-ação em um programa de pós-graduação em administração. Revista Brasileira de Pós-Graduação, 5(9), 171-205. http://dx.doi.org/10.21713/23582332.2008.v5.147

MacKenzie, S., \& Podsakoff, P. (2012). Common method bias in marketing: causes, mechanisms, and procedural remedies. Journal of Retailing, 88(4), 542-555.

Man, J. P., Weinkauf, J. G., Tsang, M., \& Sin, D. D. (2004). Why do some countries publish more than others? An international comparison of research funding, English proficiency and publication output in highly ranked general medical journals. European Journal of Epidemiology, 19(8), 811817. http://dx.doi.org/10.1023/B:EJEP.0000036571.00320.b8

Miller, A. N., Taylor, S. G., \& Bedeian, A. G. (2011). Publish or perish: academic life as management faculty live it. Career Development International, 16(5), 422-445. http://dx.doi.org/10.1108/13620431111167751

Nascimento, L. (2010). Modelos Capes de avaliação: quais as consequências para o triênio 2010- 2012? $\begin{array}{llll}\text { Administração: } \quad \text { Ensino } & \text { Pesquisa, }\end{array}$ http://dx.doi.org/10.13058/raep.2010.v11n4.130

Noy, S., \& Ray, R. (2012). Graduate students' perceptions of their advisors: is there systematic disadvantage in mentorship? The Journal of Higher Education, 83(6), 876-914. http://dx.doi.org/10.2307/23324239

Paglis, L., Green, S., \& Bauer, T. (2006). Does adviser mentoring add value? A longitudinal study of mentoring and doctoral student outcomes. Research in Higher Education, 47(4), 451-476. http://dx.doi.org/10.1007/s11162-005-9003-2 
Patrus, R., Dantas, D. C., \& Shigaki, H. B. (2015). O produtivismo acadêmico e seus impactos na pósgraduação stricto sensu: uma ameaça à solidariedade entre pares?/Academic productivity and its impacts in postgraduate programs: is it a threat to solidarity between peers? Cadernos EBAPE. $B R, 13(1), 1-32$. http://dx.doi.org/10.1590/1679-39518866

Phelan, S., Ferreira, M., \& Salvador, R. (2002). The first twenty years of the Strategic Management Journal. Strategic Management Journal, 23(12), 1161-1168. http://dx.doi.org/10.1002/smj.268

Plataforma Lattes. (2016). Evolução da formação de mestres e doutores no Brasil. Recuperado em 9 de agosto, 2016, de http://estatico.cnpq.br/painelLattes/evolucaoformacao/

Punyanunt-Carter, N., \& Wrench, J. (2008). Advisor-advisee three: graduate students' perceptions of verbal aggression, credibility, and conflict styles in the advising relationship. Education, 128(4), 579-587.

Rond, M., \& Miller, A. (2005). Publish or perish. Bane or boon of academic life? Journal of Management Inquiry, 14(4), 321-329. http://dx.doi.org/10.1177/1056492605276850

Scimago Journal \& Country Rank. (2007-2016). Recuperado em 9 de agosto, 2016, de http://www.scimagojr.com/countryrank.php

Serra, F., \& Ferreira, M. (2015). A importância da coautoria e a escolha dos coautores. Revista IberoAmericana de Estratégia, 14(4), 1-6. http://dx.doi.org/10.5585/riae.v14i4.2287

Selgen, P. (1997). Why the impact factor of journals should not be used for evaluating research. British Medical Journal, 314(7), 498-502. http://dx.doi.org/10.1136/bmj.314.7079.497

Serra, F., Fiates, G., \& Ferreira, M. (2008). Publicar é difícil ou faltam competências? O desafio de pesquisar e publicar em revistas científicas na visão de editores e revisores internacionais. Revista de Administração Mackenzie, 9(4), 32-55. http://dx.doi.org/10.1590/S1678-69712008000400004

Sheldon, K., Garton, B., Orr, R., \& Smith, A. (2015). The advisor quality survey: good college advisors are available, knowledgeable, and autonomy supportive. Journal of College Student Development, 56(3), 261-273. http://dx.doi.org/10.1353/csd.2015.0027

Shugan, S. (2013). Journal rankings: save the outlets for your research. Marketing Science, 22(4), $437-$ 441. http://dx.doi.org/10.1287/mksc.22.4.437.24904

Smith, J. (1994). Gift authorship: a poisoned chalice?. British Medical Journal, 309(6967), 1456-1457. http://dx.doi.org/10.1136/bmj.309.6967.1456

Stahl, M., Leap, L., \& Wei, Z. (1988). Publication in leading management journals as a measure of institutional research productivity. Academy of Management Journal, 31(3), 707-720. http://dx.doi.org/10.2307/256468

Stephan, P. (1996). The economics of science. Journal of Economic Literature, 34(3), 1199-1235.

Tenenbaum, H. R., Crosby, F. J., \& Gliner, M. D. (2001). Mentoring relationships in graduate school. Journal of Vocational Behavior, 59(3), 326-341. http://dx.doi.org/10.1006/jvbe.2001.1804

Thomas, S., \& Heck, R. (2001). Analysis of large-scale secondary data in higher education research: Potential perils associated with complex sampling designs. Research in Higher Education, 42(5), 517-540. http://dx.doi.org/10.1023/A:1011098109834

Trein, E., \& Rodrigues, J. (2011). O mal-estar na academia: produtivismo, o conhecimento-mercadoria. Revista Brasileira de Educação, 16(48), 769-792. http://dx.doi.org/10.1590/S141324782011000300012 
Williamson, I., \& Cable, D. (2003). Predicting early career research productivity: the case of management faculty. Journal of Organizational Behavior, 24(1), 25-44. http://dx.doi.org/10.1002/job.178

Witte, K., \& Rogge, N. (2010). To publish or not to publish? On the aggregation and drivers of research performance. Scientometrics, 85(3), 657-680. http://dx.doi.org/10.1007/s11192-010-0286-5

\section{Dados dos Autores}

\section{Christian Falaster}

Av. Francisco Matarazzo, 612, Prédio C, 05001-100, São Paulo, SP, Brasil. E-mail: christianfalaster@ gmail.com

Manuel Portugal Ferreira

Av. Francisco Matarazzo, 612, Prédio C, 05001-100, São Paulo, SP, Brasil. E-mail: manuel.portugal.ferreira@ gmail.com

Daniela Modolo Ribeiro de Gouvea

Av. Francisco Matarazzo, 612, Prédio C, 05001-100, São Paulo, SP, Brasil. E-mail: danielamodolorg@ gmail.com 